\title{
Quino e Paulo Freire, unidos pela intertextualidade: em busca de uma alternativa libertadora em tempos de educação bancária
}

\author{
Quino y Paulo Freire, unidos por la intertextualidad: en búsqueda de \\ una alternativa liberadora en tiempos de educación bancaria
}

\author{
Márcia de Fátima Xavier ${ }^{1}$ \\ Teófilo Teles Pereira de Arvelos²
}

\begin{abstract}
Resumo
Neste artigo, apresentamos a pesquisa "A ótica freiriana em Quino como recurso educacional", vinculada ao programa BIC Jr/IFTM e aplicada a estudantes do campus Patos de Minas, no segmento da disciplina de língua espanhola. $O$ objetivo da investigação realizada foi estabelecer relações intertextuais entre os conceitos teóricos de Paulo Freire e as ilustrações do artista argentino Joaquín Salvador L. Tejón, conhecido como Quino, na perspectiva do processo pedagógico de ensinoaprendizagem, a fim de buscar e propor uma alternativa eficaz ao modelo recorrente de educação bancária, criticado pelo educador brasileiro. Como referencial teórico introdutório, têm-se os livros Esto no es todo e Toda Mafalda, de Quino; e Pedagogia do oprimido, Pedagogia da autonomia, Educação como prática da liberdade, Política e educação, e A importância do ato de ler, de Paulo Freire. Quanto à abordagem, a pesquisa é qualitativa, de objetivo exploratório, visando ao estabelecimento de relações significativas no contexto educacional. Como instrumento, inicialmente, fez-se uma análise bibliográfica sobre as produções de Quino e de Freire. Em um segundo momento, foram realizadas práticas educacionais com estudantes da instituição. A análise dos resultados obtidos por meio dessas práticas indicou que a ótica freiriana aplicada a Quino é um recurso educacional eficaz e de grande benefício para a aprendizagem, com expressivo potencial de estímulo à leitura crítica dos discentes, importante pilar da pedagogia libertadora freiriana.
\end{abstract}

Palavras-chave: Paulo Freire. Quino. Educação.

\section{Resumen}

En este artículo, presentamos la investigación "A ótica freiriana em Quino como recurso educacional”, vinculada al programa BIC Jr/IFTM y aplicada a estudiantes del campus Patos de Minas, en el segmento de la asignatura de lengua española. El objetivo de la investigación fue establecer relaciones intertextuales entre los conceptos teóricos de Paulo Freire y las ilustraciones del artista argentino Joaquín Salvador L. Tejón, conocido como Quino, en la perspectiva del proceso pedagógico de enseñanza-aprendizaje, con el fin de buscar y proponer una alternativa eficaz al modelo recurrente de educación bancaria, criticado por el educador brasileño. Como referencial teórico introductorio, están los libros Esto no es todo y Toda Mafalda, de Quino; y Pedagogia do oprimido, Pedagogia da autonomia, Educação como prática da liberdade, Política e educação y $A$ importância do ato de ler, de Paulo Freire. En cuanto al abordaje, la investigación es cualitativa, de objetivo exploratorio, teniendo como objetivo el establecimiento de relaciones significativas en el contexto educativo. Como instrumento, inicialmente se hizo un análisis bibliográfico sobre las producciones de Quino y de Freire. En un segundo momento, fueron realizadas prácticas educativas con estudiantes de la institución. El análisis de los resultados obtenidos por medio de esas prácticas indicó que el enfoque freiriano aplicado a Quino es un recurso educativo eficaz y de gran beneficio para el aprendizaje de lenguas, con un potencial expresivo para estimular la lectura crítica de los estudiantes, importante pilar de la pedagogía liberadora de Freire.

Palabras clave: Paulo Freire. Quino. Educación.

\footnotetext{
${ }^{1}$ Doutora em Literaturas Modernas e Contemporâneas pela Faculdade de Letras da UFMG. Docente do Instituto Federal do Triângulo Mineiro (IFTM). Orcid: https://orcid.org/0000-0002-9636-0400. E-mail: marciaxavier@iftm.edu.br

${ }^{2}$ Estudante de Geografia na Universidade Estadual de Campinas (Unicamp). Egresso do Curso Técnico em Eletrotécnica Integrado ao Ensino Médio do IFTM, campus Patos de Minas. Orcid: https://orcid.org/0000-0002-4127-2593. E-mail: teofiloarvelos@gmail.com.
}

LínguaTec, Instituto Federal de Educação, Ciência e Tecnologia do Rio Grande do Sul, Bento Gonçalves v. 6, n. 1, p. 34-52, jun. 2021. 


\section{Introdução}

Ensino porque busco, porque indaguei, porque indago e me indago. Pesquiso para constatar, constatando, intervenho, intervindo educo e me educo. Pesquiso para conhecer o que ainda não conheço e comunicar ou anunciar a novidade.

Paulo Freire

A Constituição Federal, em seu artigo $3^{\circ}$, define o dever do Estado com a construção de "[...] uma sociedade livre, justa e solidária [...], sem preconceitos de origem, raça, sexo, cor, idade e quaisquer outras formas de discriminação" (BRASIL, 2019, p. 15). Nos artigos 205 e 206, por sua vez, a educação é interpretada e reconhecida como bem jurídico e como direito universal, haja vista seu papel fundamental para o crescimento humano e para o exercício dos demais direitos civis, políticos, sociais, econômicos e culturais dos cidadãos. É determinado que ela deve ser orientada pelos princípios da liberdade de aprender e de ensinar, de pesquisar e de divulgar o pensamento, da arte e do saber; e pelo pluralismo de ideias e de concepções pedagógicas (BRASIL, 2019).

Paralelamente, a discussão sobre políticas e gestão da educação, atravessada por embates e por processos de disputa que traduzem distintas concepções da realidade, tem sido objeto de vários estudos e pesquisas no cenário nacional e internacional (DOURADO, 2007). Essa busca por melhorias na educação tem como objetivo a necessária solução de problemas no processo de ensinoaprendizagem, o qual muitas vezes foge do que é almejado pela Constituição. Nesse cenário, o educador pernambucano Paulo Freire ${ }^{3}$, patrono da educação brasileira, autor de muitos livros que propuseram uma alternativa dialógica para o processo pedagógico, tem sido fonte de pesquisa e de inspiração para muitos desses estudos com o seu legado.

Mário Sérgio Cortella, também professor e educador brasileiro, em seu artigo "Paulo Freire: um pensamento clássico e atual", de 2011, compartilha com seus leitores um pouco da sua experiência de convívio com Paulo Freire. O escritor comenta dados da biografia de Freire de forma a justificar a atualidade do legado do patrono da educação brasileira.

\footnotetext{
${ }^{3}$ Paulo Freire (Recife, 1921 - São Paulo, 1997), em 1963, em Angicos, interior do Rio Grande do Norte, coordenou uma equipe que alfabetizou trezentos trabalhadores rurais em apenas quarenta horas. Esse foi o projeto-piloto do que seria 0 Programa Nacional de Alfabetização do governo de João Goulart, presidente que viria a ser deposto em março de 1964. Em outubro desse mesmo ano, Freire deixou o Brasil para proteger a própria vida. Apenas voltou a visitar o país em 1979, com a abertura democrática. Ao longo de sua história, recebeu 42 títulos de doutor honoris causa, além de títulos de professor emérito, distinguished educator e investigador emérito, de diversas universidades nacionais e estrangeiras, além de inúmeros prêmios, como Educação para a Paz, da Unesco, e Ordem do Mérito Cultural, do governo brasileiro. Integra o International Adult and Continuing Education Hall of Fame e o Reading Hall of Fame. (FREIRE, 2020, terceira capa)
} 
Neste ano de 2021, uma década após a publicação do artigo de Cortella, comemora-se o centenário de nascimento de Paulo Freire, e seu legado se mostra tão atual como sempre. Reconhecido como um clássico, "[...] seu trabalho não perdeu vitalidade, não perdeu a irrigação, não perdeu a conexão com a vida e com o sangue que a vida partilha e emana." (CORTELLA, 2011, p. 11-12) Sendo clássico, as questões-chave que o permeiam ainda se mostram visíveis nos dias de hoje, como a existência de oprimidos e de opressores. Nesse sentido, "Paulo Freire não era (e nem poderia ser) uma unanimidade; [ele] fez uma opção no enfrentamento político e existencial [...]" (CORTELLA, 2011, p.7) mediante uma pedagogia dialógica que descobria e revelava corajosamente o mundo das injustiças e que, por meio dessa estratégia, promovia a paz.

Opção semelhante fez o pensador, historiador e cartunista argentino Joaquín Salvador L. Tejón ${ }^{4}$, de nome artístico Quino, falecido em setembro de 2020, enquanto a pesquisa que fundamentou este artigo era realizada, gerando uma grande comoção por parte de admiradores e de pesquisadores de seu trabalho. Quino, assim como Freire, não ficou alheio à crise política pela qual sua pátria atravessava. Sua obra é, na realidade, marcada por reflexões de cunho crítico e reflexivo sobre importantes questões socioeconômicas, educacionais, culturais e políticas. Suas produções, ao exemplo da famosa personagem Mafalda, expõem sem temor as contradições das classes dominadoras e posicionam-se a favor dos mais empobrecidos e dos mais discriminados (ARVELOS; XAVIER, 2020).

Podendo ser considerada um modelo freiriano de educando, Mafalda mantém em si o gosto pela rebeldia, pela curiosidade; arrisca-se, aventura-se; não aceita o poder apassivador do opressor. Pela produção literária de Quino, depreende-se que, a despeito de Mafalda não ter professores que compartilhem do pensamento de Freire de que ensinar "[...] não é transferir conhecimento, mas criar possibilidades para a sua produção ou a sua construção." (FREIRE, 2020a, p. 24, grifo do autor), ela não se contém em exigir de sua professora uma abordagem crítica e com possibilidades de participação dos discentes. Estabelecendo-se essas possibilidades, como cocriador, o educando, ao lado do educador, transforma-se em real sujeito da (re)construção do saber ensinado.

\footnotetext{
4 Joaquín Salvador Lavado Tejón (Mendoza - Argentina, 1932 - 2020), com grande vocação para o desenho, ao terminar a escola primária foi matriculado na Escola de Belas Artes de Mendoza. Em seguida, ingressou na Faculdade de Belas Artes, mas, em 1949, resolveu abandonar o curso e se dedicar ao desenho de quadrinhos e de humor gráfico. Quino criou vários personagens, mas a que mais se destacou foi a menina inteligente e contestadora Mafalda, criada em 1964. Em 1973, Quino optou por descontinuar suas tirinhas da Mafalda, pois segundo ele, "a Mafalda virou um carimbo" e isso não Ihe agradava. Em 1976, mudou-se para Milão, na Itália, e seu trabalho aos poucos foi conquistando o mundo. Em 1977, a pedido da UNICEF, as tirinhas da Mafalda ilustraram a Edição Internacional da Campanha Mundial de Declaração dos Direitos da Criança. Em 1982, Quino foi eleito o "Desenhista do Ano". Nesse mesmo ano, foram publicados no Brasil os três primeiros livros da Mafalda. O trabalho de Quino recebeu vários prêmios internacionais, entre eles, o "Prêmio das Astúrias de Comunicação e Humanidades", na Espanha, em 2014.

FRAZÃO, Dilva. Disponivel em: https://www.ebiografia.com/quinol. Acesso em: 12 mar. 2021.
}

LínguaTec, Instituto Federal de Educação, Ciência e Tecnologia do Rio Grande do Sul, Bento Gonçalves v. 6, n. 1, p. 34-52, jun. 2021. 
Foi nessa perspectiva, de uma pedagogia da autonomia, que o projeto de pesquisa que aqui será apresentado foi realizado entre orientador-orientando. Ancorado na certeza da importância do papel do educador como aquele que não apenas deposita conteúdos em uma orientação bancária de educação, mas que também ensina a pensar de forma crítica, não mecanicista, mesmo que, às vezes, pense errado, uma vez que ensinar exige consciência do inacabamento, Paulo Freire relata a importância da produção do conhecimento ainda não existente. Para o educador, há dois momentos do ciclo gnosiológico:

[...] 0 em que se ensina e se aprende o conhecimento já existente e o em que se trabalha na produção do conhecimento ainda não existente. A 'dodiscência' - docência-discência - e a pesquisa, indicotomizáveis, são assim práticas requeridas por esses momentos do ciclo gnosiológico. (FREIRE, 2020a, p. 30)

Comungando da dodiscência, o trabalho de pesquisa realizado visou aplicar a ótica freiriana a Quino no contexto educacional, de modo a propiciar a formação discente na via da pedagogia que liberta e que promove a esperança, em vez da que corrobora a opressão. De cunho qualitativo, de objetivo exploratório e objetivando o estabelecimento de relações significativas, o projeto desenvolveu três práticas educacionais entre os meses de março a dezembro de 2020 no IFTM, campus Patos de Minas, envolvendo 147 estudantes, sendo distribuídos da seguinte forma: 32 discentes do $3^{\circ}$ ano do Técnico em Logística integrado ao ensino médio; 31 do $3^{\circ}$ ano Técnico em Eletrotécnica integrado ao ensino médio; 24, do $2^{\circ}$ ano do Técnico em Mineração integrado ao ensino médio; 25, do $2^{\circ}$ ano do Técnico em Logística integrado ao ensino médio; 32 , do $2^{\circ}$ ano do Técnico em Eletrotécnica integrado ao ensino médio e 3, da turma de língua espanhola, nível básico I, do Centro de Idiomas (CENID) da instituição.

Como instrumento, em um primeiro momento, fez-se uma análise bibliográfica sobre as produções de Freire e de Quino segundo a abordagem do pós-doutor em Educação e pesquisador João José Saraiva da Fonseca, isto é, "[...] a partir do levantamento teórico de referências já analisadas [...] com o objetivo de recolher informações ou conhecimentos prévios sobre o problema a respeito do qual se procura a resposta" (FONSECA, 2002, p. 32). Em um segundo momento, desenvolveram-se práticas educacionais, todas de maneira on-line, devido à suspensão emergencial das aulas presenciais da instituição em março de 2020 em decorrência da pandemia do COVID-19.

\section{Quino e Freire: autores convergentes}

Conforme teoriza Paulo Freire, a indagação, a busca e a pesquisa fazem parte da prática docente. "Não há ensino sem pesquisa e pesquisa sem ensino" (FREIRE, 2020a, p. 30). Assumindo-se 
como professor-pesquisador e tendo ciência de que ensinar exige rigorosidade metódica, "o educador democrático não pode negar-se o dever de, na sua prática docente, reforçar a capacidade crítica do educando, sua curiosidade, sua insubmissão" (FREIRE, 2020a, p. 28). Diferentemente desse, também chamado por Freire de educador progressista ou educador "problematizador", há o educador "bancário". Infelizmente, trata-se de um modelo de educador que é encontrado em várias regiões e instituições de ensino do país, nas quais os discentes não têm o direito de questionar, de discutir, de apresentar suas críticas e sugestões. Nesse modelo de educação, o educando tem tão somente o dever e a obrigação de receber a educação, a qual lhe é entregue mediante depósitos.

Em lugar de comunicar-se, o educador faz "comunicados" e depósitos que os educandos, meras incidências, recebem pacientemente, memorizam e repetem. Eis aí a concepção "bancária" da educação, em que a única margem de ação que se oferece aos educandos é a de receberem os depósitos, guardá-los e arquivá-los. Margem para serem colecionadores ou fixadores das coisas que arquivam. (FREIRE, 2020b, p. 80-81)

Nessa concepção da educação, "o 'saber' é uma doação dos que se julgam sábios aos que julgam nada saber" (FREIRE, 2020b, p. 81). O educador tem a tarefa de "encher" os educandos com os conteúdos da sua narração: "a tônica da educação é preponderantemente esta — narrar, sempre narrar" (FREIRE, 2020b, p. 79). Ou seja, não há superação, não há protagonismo do educando como tanto teorizava o educador, mas, sim, a diminuição e/ou a anulação do poder criador do educando, dando lugar a sua ingenuidade em detrimento de sua criticidade.

Refletindo a sociedade opressora, sendo dimensão da "cultura do silêncio", a "educação" "bancária" mantém e estimula a contradição.

Daí, então, que nela:

a) o educador é o que educa; os educandos, os que são educados;

b) o educador é o que sabe; os educandos, os que não sabem;

c) o educador é o que pensa; os educandos, os pensados;

d) o educador é o que diz a palavra; os educandos, os que escutam docilmente;

e) o educador é o que disciplina; os educandos, os disciplinados;

f) o educador é o que opta e prescreve sua opção; os educandos, os que seguem a prescrição; g) o educador é o que atua; os educandos, os que têm a ilusão de que atuam, na atuação do educador;

h) o educador escolhe o conteúdo programático; os educandos, jamais ouvidos nesta escolha, se acomodam a ele;

i) o educador identifica a autoridade do saber com sua autoridade funcional que opõe antagonicamente à liberdade dos educandos; estes devem adaptar-se às determinações daquele;

j) o educador, finalmente, é o sujeito do processo; os educandos, meros objetos. (FREIRE, 2020b, p. 82-83)

Na esteira de Paulo Freire, a proposta da pesquisa foi contribuir para a superação desse modo falho de ensino-aprendizagem da educação bancária, propondo um recurso didático alternativo e eficaz 
que fosse muito além de transmitir conteúdo, mas que também instigasse curiosidade, participação e senso crítico. Para isso, foram usados excertos de livros de Paulo Freire e desenhos de Quino, relacionados por meio da intertextualidade.

Conforme sinaliza Sandra Cavalcante, em sua tese de doutorado, a intertextualidade é um fenômeno intrínseco à experiência humana de construção de sentido (CAVALCANTE, 2009, p. 12), o qual pode ser aplicado como abordagem a fins didáticos. Com efeito, os processos de interação e de vivência cultural humana se instituem intertextualmente, o que permite que a intertextualidade seja compreendida de forma ampla, não se limitando apenas ao campo de estudo da linguística (CAVALCANTE, 2009, p. 20-21), mas também podendo ser usada como recurso no processo de ensinoaprendizagem, por se tratar de um mecanismo que se relaciona à cognição e à linguagem humana (CAVALCANTE, 2009, p. 17).

Como já mencionado, a "[...] existência de uma intertextualidade significativa entre as produções de Paulo Freire e de Quino pode ser presumida pelas semelhanças entre suas visões de mundo." (ARVELOS; XAVIER, 2020, p. 2). O objeto de análise da pesquisa não foi de estabelecer de que modo se deu o nível de intertextualidade entre os autores, mas, vale ressaltar, a contemporaneidade dos dois. Desafiadora e indagadora, a menina Mafalda, de apenas 6 anos de idade, cujas histórias foram criadas de 1964 a 1973 - período que compreende os cinco anos de exílio de Paulo Freire no Chile e que the renderam a escrita de Pedagogia do oprimido (1968) - atende às expectativas do propósito freiriano de "ler o mundo, de ler a palavra e assim ler a leitura do mundo anteriormente feita" (FREIRE, 2001, p. 260). Reconhecendo-se como arquiteta de sua própria prática cognoscitiva,

\footnotetext{
Mafalda denunciou uma dura realidade, muito distante dos elevados padrões morais que a política deveria representar. Isso foi reforçado por sua defesa de uma posição do Terceiro Mundo que representava os excluídos da ordem internacional. Sua voz foi vista como a expressão da consciência humanista da nova geração politicamente comprometida. (COSSE, 2014, p. 55, tradução nossa)
}

Assim, percebe-se que Mafalda é, portanto, um exemplo de estudante almejado por Paulo Freire: aquele aluno e aquela aluna que, além de saberem ler um livro, sabem ler o mundo. Aqueles e aquelas estudantes que, além de interpretar uma fórmula matemática, sabem interpretar criticamente a realidade em que vivem.

Nessa lógica, a leitura de Mafalda por estudantes se mostra como uma aliada na promoção da pedagogia libertadora freiriana. Com efeito, foi pensando nos oprimidos que Freire escreveu seu clássico ensaio, como uma maneira de caminhar com os educandos na construção de uma teoria que 
visasse à fundamentação e à reflexão da própria ação libertadora, por intermédio da educação (PADILHA, 2008, p. 25). Desse modo, o método do educador brasileiro, que busca libertar os educandos da opressão e dos preconceitos, ganha força nos desenhos de Quino, uma vez que

Mafalda [...] representou a consciência moral forjada pelo mandato igualitário que clamava
pela inclusão social e que considerava o ensino público e obrigatório como forma de
proporcionar melhores oportunidades a todos, e expressou um sentimento de culpa pelo
racismo de sua própria classe. (COSSE, 2014, p. 60 , tradução nossa)

A intertextualidade, destarte, apresenta-se como ferramenta eficaz na aplicação da ótica freiriana em Quino como recurso educacional, especialmente na aprendizagem de línguas, como explorado pelo projeto de pesquisa apresentado (ARVELOS; XAVIER, 2020, p. 3).

Nas práticas educacionais desenvolvidas, esse recurso intertextual foi usado de duas formas distintas: para as turmas de cursos técnicos integrados ao ensino médio, a modalidade de aplicação da pesquisa feita às turmas de segundos e de terceiros anos foi a de atividade avaliativa escrita, desenvolvida por meio do recurso Formulários Google. Para a turma de espanhol do CENID, foi conduzido um debate entre os alunos, com duração aproximada de uma hora, realizado por intermédio da plataforma Google Meet.

\section{Desenvolvimento}

Quando o projeto de pesquisa foi submetido à análise, em novembro de 2019, a doença COVID19, causada pelo novo coronavírus (SARS-CoV-2), era uma enfermidade, até então, pouco expressiva; desconhecida em todo o globo. O cronograma de execução da aplicação da ótica freiriana em Quino englobava não apenas estudantes do IFTM, campus Patos de Minas, instituição pública, federal, que tem como missão "Ofertar a Educação Profissional e Tecnológica por meio do Ensino, Pesquisa e Extensão promovendo o desenvolvimento na perspectiva de uma sociedade inclusiva e democrática" (IFTM, 2016, p. 5), mas, também, estudantes de outra instituição pública da cidade, da esfera estadual. Mas, logo em dezembro, foram repercutidas notícias da pandemia, ainda que do outro lado do planeta, e que atingiu todo o mundo em pouco tempo. Muito rapidamente, três dias após a suspensão das aulas presenciais, o IFTM, campus Patos de Minas, se organizou para seguir com as aulas de maneira remota, e foi assim que a pesquisa foi realizada com estudantes do campus. Alcançar, de maneira online, os educandos almejados da rede estadual se tornou uma realidade muito distante, diante de todas as dificuldades de acesso a esse tipo de prática que esses estudantes enfrentavam. Desse modo, como não há esses dados para fins de comparação, não é objeto deste estudo analisar diferenças de 
condições oferecidas aos educadores-educandos desses dois níveis de instituição, ou o perfil de estudantes e até mesmo de educadores que cada uma delas recebe; a realidade das práticas remotas da pandemia falam por si próprias.

Tendo o público das duas turmas de estudantes concluintes do ensino médio integrado ao técnico, a tarefa escrita foi a mesma. Primeiramente, foram apresentados aos estudantes os textos a seguir:

As sociedades a que se nega o diálogo - comunicação - e, em seu lugar, se lhes oferecem "comunicados", resultantes de compulsão ou "doação", se fazem preponderantemente "mudas". O mutismo não é propriamente inexistência de resposta. É resposta a que falta teor marcadamente crítico.

Não há realmente, como se possa pensar em dialogação com a estrutura do grande domínio, com o tipo de economia que o caracterizava, marcadamente autárquico. A dialogação implica uma mentalidade que não floresce em áreas fechadas, autarquizadas. Estas, pelo contrário, constituem um clima ideal de antidiálogo. (FREIRE, 2020, p. 93-94)

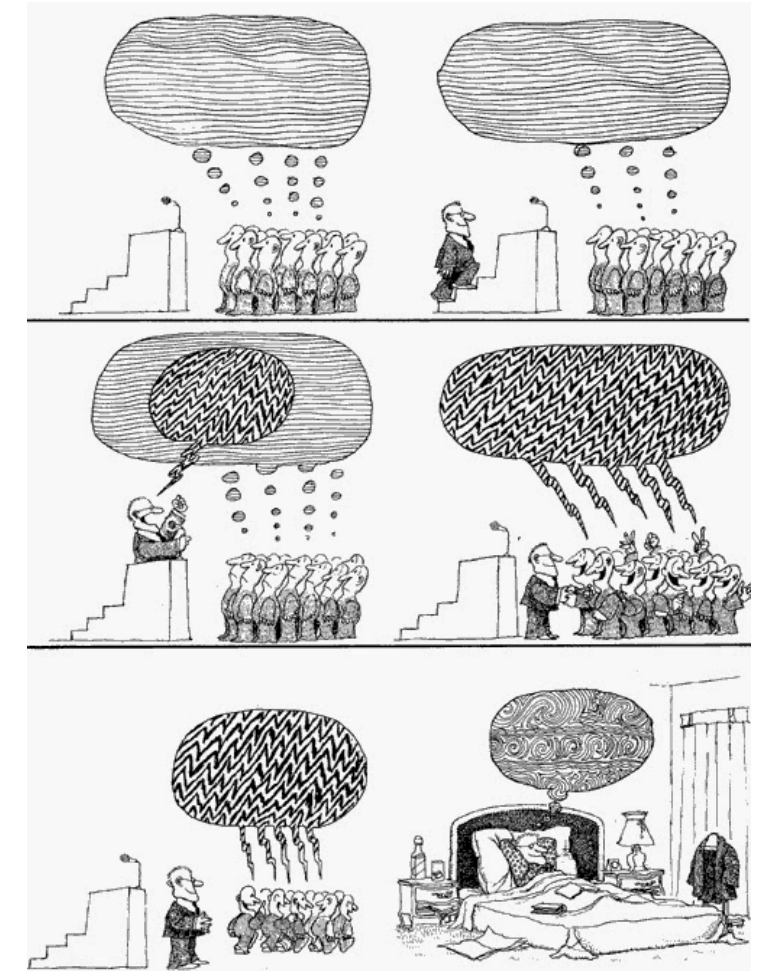

Figura 1. Produção de Quino utilizada em prática com os terceiros anos.

Fonte: Esto no es todo, Quino.

A partir desses textos, foram feitas as perguntas a seguir, conforme Figura 2, que buscavam levar o estudante a refletir e a estabelecer relações entre eles. No caso das turmas do ensino médio, as questões foram aplicadas como atividade avaliativa da disciplina de língua espanhola; no curso do Centro de Idiomas, não houve o critério de avaliação. 


\section{LÍNGUATEC}

2) A partir de la lectura del Texto 1, marca la opción correcta.

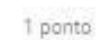

A) Los llamados "comunicados" contribuyen a la promoción del diálogo y la comunicación en las sociedades democráticas.

B) Los llamados "comunicados" contribuyen a la aparición del llamado "mutismo".

C) En el texto, se defiende la tesis de que algunas sociedades deben luchar contra el diálogo.

D) Según el texto, el diálogo implica una mentalidad que no florece en áreas cerradas; por lo tanto, es preferible que las discusiones políticas se realicen al aire libre.

E) En el texto, se defiende la tesis de que el anti-diálogo surge de una sociedad en la que se promueve el pensamiento crítico, lo que a su vez conduce a conflictos civiles.

3) ¿El Texto 2 presenta una sociedad en que hay diálogo, según la concepción de diálogo del Texto 1? Justifique.

Sua resposta

4) ¿Cómo las dos escenas del medio del cartoon se relacionan con el 1 ponto concepto freireano de mutismo. presente en el Texto 1? Explique.

Sua resposta

5) ¿Qué significa la representación de pensamiento en la última escena del 1 ponto cartoon. en que la personaje está en su cama? ¿Por que es distinta de la representación del discurso en la tercera escena?

Sua resposta

Figura 2. Atividade de intertextualidade aplicada aos terceiros anos.

Fonte: Material produzido pelos autores.

A opção por aplicar a pesquisa como prática avaliativa da disciplina de língua espanhola se mostrou como uma boa alternativa para o processo avaliativo dessas duas turmas, que naquele momento da aplicação da pesquisa tinham como conteúdo programático os cartuns, as charges, as tiras e também os monólogos de humor. Essas questões, assim como as demais propostas durante a aplicação da pesquisa, foram elaboradas pelo bolsista do projeto, que no decorrer da pesquisa se mostrou cocriador extremamente produtivo no processo de "dodiscência".

Em consonância com a ótica freiriana sobre sistemas de avaliação, dar ao orientando a liberdade de criar as questões se mostrou como prática pedagógica que não vem de cima para baixo; mas de forma dialógica. $O$ objetivo da aplicação do formulário não era silenciar os estudantes com questões que estivessem muito além das suas capacidades, senão fazê-los pensar e refletir durante o processo

LínguaTec, Instituto Federal de Educação, Ciência e Tecnologia do Rio Grande do Sul, Bento Gonçalves 
avaliativo. "A questão que se coloca a nós é lutar em favor da compreensão e da prática da avaliação enquanto instrumento de apreciação do que fazer de sujeitos críticos a serviço, por isso mesmo, da libertação e não da domesticação. Avaliação em que se estimule o falar a como caminho do falar com." (FREIRE, 2020a, p. 114, grifo do autor). Essa proposta de atividade atuou como processo de escuta, uma vez que não foram entregues/depositados apenas comunicados aos discentes. As questões discursivas abriram espaço para que os estudantes fizessem suas próprias análises a partir da leitura dos textos e também por meio de suas leituras de mundo.

Com efeito, o fragmento destacado do educador Paulo Freire para essa proposta de atividade aborda exatamente a negativa cultura dos comunicados, que geram sociedades predominantemente mudas a partir do momento em que os diálogos deixam de existir para que sejam apenas depositados comunicados. A tirinha de Quino (Fig. 1) também apresenta justamente esse tipo de sociedade, em que não há diálogo. No desenho, os receptores do discurso que está sendo proferido não são escutados, não é dada a eles a possibilidade e o espaço para manifestar suas opiniões. Apenas foram convencidos pelo interesse do orador; discurso esse que, conforme pode ser identificado na última cena, sequer representa as suas reais intenções. Não há crítica, não há interlocução, ocorre apenas o comunicado do opressor, propiciando o mutismo dos que ali estão. Essa tira de Quino ainda coloca em evidência a falsa "generosidade" opressora do comunicador em decorrência do mutismo que é provocado em seu público. Generosidade que, nas palavras de Freire, "[...] se nutre da morte, do desalento e da miséria." (FREIRE, 2020b, p. 42)

Aos estudantes dos segundos anos do ensino médio foi aplicada uma única questão, a qual inter-relacionava um excerto da obra $A$ importância do ato de ler: em três artigos que se completam, de Paulo Freire, e um desenho de Mafalda feito por Quino, conforme exposto a seguir:

O trabalho que transforma nem sempre dignifica os homens e as mulheres. Só o trabalho livre nos dá valor. Só o trabalho com o qual estamos contribuindo para a criação de uma sociedade justa, sem exploradores nem explorados, nos dignifica.

$\mathrm{Na}$ época colonial, o nosso trabalho não era livre. Trabalhávamos para os interesses dos colonialistas que nos exploravam. Eles se apropriaram das nossas terras e da nossa força de trabalho e enriqueceram à nossa custa. Quanto mais ricos ficavam eles, tanto mais pobres ficávamos nós. Eles eram a minoria exploradora. Nós éramos a maioria explorada. Hoje, somos independentes. Já não trabalhamos para uma minoria. Trabalhamos para criar uma sociedade justa. Temos muito o que fazer ainda (FREIRE, 2019, p.80). 


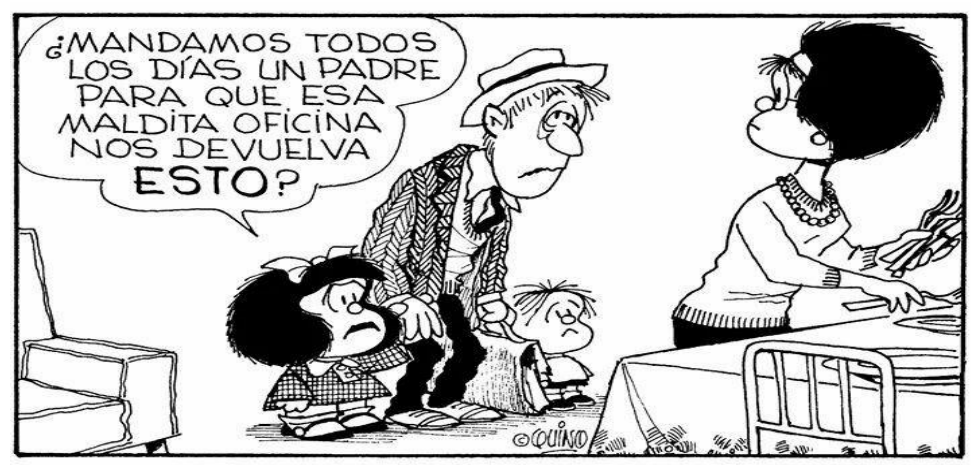

Figura 3. Desenho de Quino utilizado em prática educacional com os segundos anos. Fonte: Toda Mafalda, Quino.

Em sequência, foi solicitado que se marcasse a afirmação verdadeira contida na questão a seguir.

a) o pai de Mafalda não seria considerado por Paulo Freire um "explotado", pois, conforme Texto 1, os trabalhos não livres somente existiam na época colonial.

b) Mafalda compartilha da visão de Paulo Freire, presente no Texto 1, de que nem todos os trabalhos trazem dignidade, pois, conforme evidenciado no Texto 2, ela considera que seu pai é explorado no ambiente de trabalho.

c) as visões de Mafalda e Paulo Freire nos textos 1 e 2 são contrárias, pois, apesar de

o pai da personagem exercer um "trabajo libre" (ele trabalha em um escritório), Mafalda considera que essa profissão não lhe dá valor.

d) Paulo Freire consideraria que a familia de Mafalda, ilustrada no Texto 2, está se

tornando cada vez mais empobrecida, pois, conforme Texto 1, quanto mais os patrões exploram seus funcionários, mais estes se empobrecem.

Figura 4. Questão aplicada aos segundos anos. Fonte: Material produzido pelos autores.

A citação utilizada para a realização dessa atividade está no artigo "O povo diz a sua palavra ou a alfabetização em São Tomé e Príncipe". Nele, o educador brasileiro relata a sua experiência de alfabetização de adultos no contexto do país africano. Entendendo a educação como ato político, Freire relata a importância de se estar em consonância, enquanto assessor, com o governo assessorado. Textos com temáticas relacionadas à exploração laboral, como a vivenciada pelo pai da personagem Mafalda, e que é realidade em muitos lares tanto do Brasil quanto da Argentina, assim como de São Tomé e Príncipe, aparecem em vários de seus escritos. O fragmento trabalhado com os segundos anos faz parte de um conjunto de textos que compunham o Segundo Caderno de Cultura Popular, material utilizado no processo de pós-alfabetização nessa experiência africana. Estes foram 
[...] escritos em linguagem simples, jamais simplista, que trata uma temática ampla e variada, ligada, toda ela, ao momento atual do país. 0 que se pretende com esses textos [...] é que eles se entreguem à curiosidade crítica dos educandos e não que sejam lidos mecanicamente. A linguagem do texto é desafiadora e não sloganizadora. O que se quer é a participação efetiva do povo enquanto sujeito, na reconstrução do país, a serviço de que a alfabetização e a pósalfabetização se acham. (FREIRE, 2019, p. 52)

O questionamento feito pela personagem Mafalda materializa a teorização de Paulo Freire. A personagem de Quino participa efetivamente enquanto sujeito que não aceita as amarras da violência opressora e clama pela recuperação da humanidade e da dignidade do pai. Mafalda, que não vive na época colonial, tem total consciência de que ainda há um longo caminho a ser percorrido, ainda nos seus dias.

Para os alunos do Centro de Idiomas não houve aplicação de formulário, mas uma discussão oral a partir de excertos de obras de Paulo inter-relacionados com tirinhas da personagem Mafalda e cartuns de Quino. Duas perguntas norteadoras foram feitas a cada par de textos dos distintos autores em análise. Em seguida, os discentes tinham liberdade para comentar os textos e discutir as questões, construindo, coletivamente, possíveis respostas para essas perguntas.

A seguir, exemplos de textos de Paulo Freire e de Quino utilizados na prática no CENID:

Como tentar explicar a miséria, a dor, a fome, a ignorância, a enfermidade crônica, dizendo, cinicamente, que o mundo é assim mesmo; que uns trabalham mais, com competência, por isso tem mais e que é preciso ser pacientes, pois um dia as coisas mudam? Há uma imoralidade radical na dominação, na negação do ser humano, na violência sobre ele, que contagia qualquer prática restritiva de sua plenitude e a torna imoral também.

Imoral é a dominação econômica, imoral é a dominação sexual, imoral é o racismo, imoral é a violência dos mais fortes sobre os mais fracos. Imoral é o mando das classes dominantes de uma sociedade sobre a totalidade de outra, que delas se torna puro objeto, com sua maior ou menor dose de conivência. (FREIRE, 1993, p. 92)
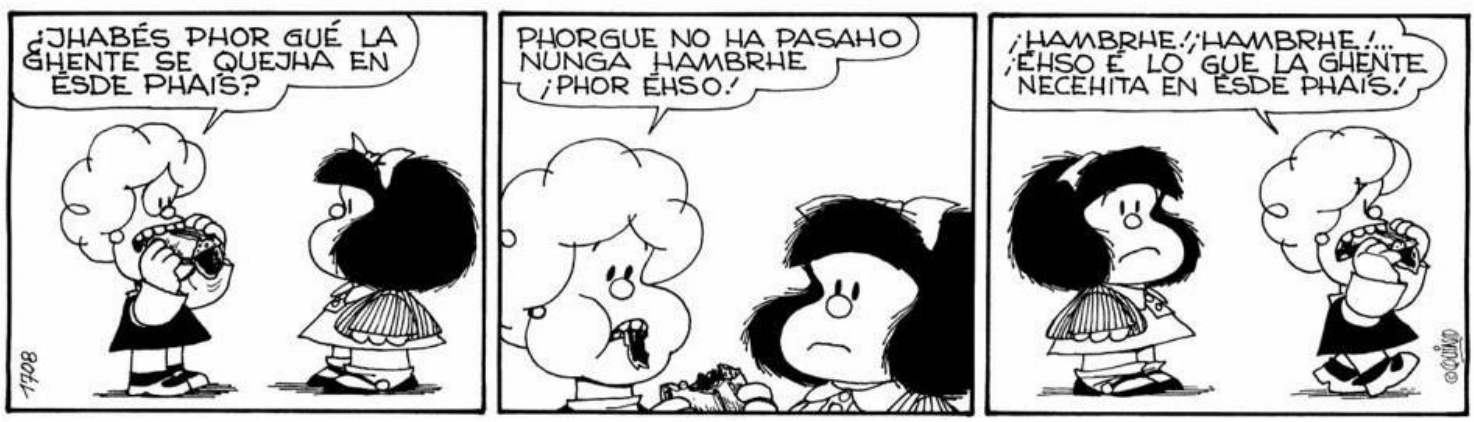

Figura 5. Tira de Quino utilizada em prática educacional com turma do Cenid. Fonte: Toda Mafalda, Quino.

Para os textos acima, escritos em variante não formal da língua espanhola, foram apresentadas as seguintes perguntas norteadoras: “ ¿Susanita tiene un pensamiento de dominación?” (Susanita tem 
um pensamento de dominação?); "Según Paulo Freire, ¿se puede decir que el pensamiento de Susanita es inmoral?" (Segundo Paulo Freire, pode-se dizer que o pensamento de Susanita é imoral?). Durante a prática discursiva aplicada, os estudantes tiveram a oportunidade de manifestar suas opiniões com relação aos textos e concluíram que, sim, Susanita tem um pensamento de dominação egoísta, e é manifestado de forma ainda mais expressiva devido à condição socioeconômica favorecida da personagem, e que seu pensamento também pode ser considerado imoral. A prática ainda proporcionou a reflexão de que esse tipo de pensamento não se restringe à personagem Susanita, mas a um grande número de pessoas reais, que fogem do plano ficcional de Quino, mas que estão bem presentes na nossa realidade.

\section{Resultados e discussão}

Os resultados da prática educacional aplicada aos terceiros anos se mostraram bastante positivos. A questão 2 da Figura 2 foi respondida da seguinte forma: das 32 respostas obtidas no $3^{\circ}$ ano do Técnico em Logística integrado ao ensino médio, 31 (aproximadamente 97\%) acertaram a questão, marcando a alternativa $\mathrm{B}$. Apenas 1 aluno (aproximadamente 3\%) respondeu incorretamente à questão, marcando a alternativa A, conforme Anexo A. Na turma do Técnico em Eletrotécnica, das 31 respostas obtidas, 22 estavam corretas (aproximadamente 71\%), sendo que as demais foram divididas entre a letra A (8 respostas, aproximadamente $26 \%$ ) e a letra $\mathrm{E}$ (1 resposta, aproximadamente $3 \%$ ), Anexo B. Assim, o índice geral de acertos foi de 84\%.

Interpreta-se que os alunos que indicaram erroneamente a alternativa A como correta (14,3\% do total de participantes) tiveram dificuldade de compreender o significado dos chamados "comunicados", conceito abordado por Paulo Freire, e que o estudante que selecionou a alternativa $E$ ( $1,6 \%$ do total de participantes) o fez ao acaso, não lendo previamente o excerto do educador brasileiro.

As questões 3 e 4 foram respondidas por ambas as turmas de modo muito satisfatório, gerando respostas críticas e reflexivas. Um exemplo de resposta de um aluno do Técnico em Eletrotécnica, Anexo C, para a pergunta 3 foi: "O Texto 2 não apresenta uma sociedade em que há diálogo, segundo a concepção de diálogo do Texto 1, uma vez que o povo não foi ouvido pelo orador; este, na verdade, foi o único a que foi permitido falar, propagando, assim, sua visão, e desconsiderando as opiniões da população." À pergunta 4, um estudante do Técnico em Logística, Anexo D, respondeu: "Elas [as cenas do meio do cartum] se relacionam com este conceito [freiriano de mutismo] pois fica evidente que houve 
apenas um monólogo, um discurso de apenas uma pessoa para uma multidão que nem mesmo questionou ou formou críticas àquilo que foi dito, sendo considerado, portanto, mutismo."

Já a questão 5 apresentou índice de acertos mediano em ambas as turmas, pois exigia uma interpretação mais profunda e atenta. Ainda assim, foram obtidas respostas com leitura e criticidade excelentes, como esta, de um aluno do Técnico em Logística, Anexo E: "Eu penso que nessa cena, o político está com seus reais pensamentos que diferem do que ele disse, provavelmente seu discurso foi sobre algo que a população gostaria de ouvir, mas ele, na verdade, possui uma maneira diferente e distorcida de pensar".

Os resultados da prática com os segundos anos também foram positivos. A questão apresentada na Figura 4 foi respondida desta maneira: na turma do Técnico em Eletrotécnica, Anexo F, 23 estudantes $(71,9 \%)$ acertaram, indicando a alternativa "b", e 9 erraram $(28,1 \%)$, indicando as alternativas "c" e "d"; na turma do Técnico em Logística, Anexo G, 23 estudantes (92\%) acertaram e 2 (8\%) erraram, indicando as alternativas "c" e "d"; na turma do Técnico em Mineração, Anexo H, 15 estudantes (62,5\%) acertaram e 9 (37,5\%) erraram, também indicando as alternativas "c" e "d". Nas três turmas, nenhum aluno marcou a alternativa "a". O índice geral de acertos foi de $75,3 \%$, considerado bom.

Entende-se que os estudantes que selecionaram a alternativa "c" (16\% do total de participantes) não conseguiram compreender o significado do conceito de trabalho livre apresentado por Freire: 0 trabalho em que não há exploração, em que não há a dinâmica de opressores e de oprimidos. Para esses alunos, o pai de Mafalda exerceria um trabalho livre, o que não se confirma. Além do mais, notase uma falha de interpretação intertextual, pois as visões de Freire e Mafalda não são contrárias, mas, sim, convergentes.

Por outro lado, entende-se que aqueles que marcaram a alternativa "d" ( $8,6 \%$ do total de participantes) tiveram tanto uma má interpretação intertextual quanto uma má interpretação de cada texto, isoladamente. Não há indicativos para o empobrecimento da família de Mafalda no referido Texto 2 (Figura 4), nem menções no Texto 1 (excerto de Freire) que afirmariam que quanto mais os patrões exploram seus funcionários, mais estes se empobrecem — essa associação se refere, na verdade, aos colonialistas e ao colonizados.

Os resultados obtidos com a prática aplicada à turma do Centro de Idiomas foram razoáveis, mas de difícil análise. Entende-se que a dinâmica virtual em que o debate foi conduzido desestimulou a participação dos discentes, os quais teriam uma participação mais interessada e espontânea em um formato presencial de atividade. Ainda assim, isso não impediu que respostas corretas e coletivamente 
construídas fossem elaboradas, de modo a contribuir para a capacidade de leitura em espanhol dos alunos e para seu desenvolvimento interpessoal.

\section{Conclusão}

Conclui-se que as três práticas desenvolvidas comprovaram a forte convergência intertextual entre as produções do cartunista argentino Joaquín Salvador L. Tejón (Quino) e as do educador brasileiro Paulo Freire, mediante as boas respostas, as argumentações e as discussões dos educandos. O diálogo entre os textos, nesse âmbito, mostrou-se como ferramenta eficaz na aplicação da ótica freiriana em Quino, a qual pode ser utilizada como recurso educacional, especialmente nas disciplinas de linguagens, como alternativa à pedagogia bancária.

O envolvimento tímido dos discentes do Centro de Idiomas não contesta essa percepção. 0 desestímulo à participação de atividades foi observado em toda a instituição desde o início do ensino remoto, em março de 2020, uma vez que muitos estudantes tiveram dificuldades de acesso à internet e/ou passaram a ter um rendimento escolar menor (IFTM, 2020). Dessa forma, entende-se que a inibição dos alunos da turma de espanhol não pode ser interpretada como um indicador de falha do recurso educacional investigado, senão uma manifestação própria do contexto em que ela foi realizada.

Os estudantes do ensino médio do IFTM, campus Patos de Minas, de maneira geral, tiveram bom desempenho nas atividades e esse resultado já era bastante previsível, considerando o perfil de comprometimento e de envolvimento crítico que muitos deles manifestam nas suas rotinas diárias de sala de aula e nos vários projetos que são realizados na instituição. A pesquisa, de maneira bastante positiva, ainda nos possibilitou observar que a abordagem que une Quino e Freire também pode ser empregada como estratégia avaliativa. Além do mais, percebeu-se que esse recurso estimulou-os a ler criticamente não só os textos abordados, mas também a realidade que os circunda.

\section{Referências}

ARVELOS, T. T. P.; XAVIER, M. F. S. A ótica freiriana em Quino como recurso educacional. EnPE Encontro de Pesquisa e Extensão, Patrocínio, v. 7, n. 1, 2020. Disponível em: $<$ http://enpe.iftmpatrocinio.com.br/index.php/enpe/article/view/168>. Acesso em: 10 mar. 2021.

BRASIL. [Constituição (1988)]. Constituição da República Federativa do Brasil. Brasília: Supremo Tribunal Federal, Secretaria de Documentação, 2019. 577 p.

BRIGHENTE, F.; MESQUIDA, P. Paulo Freire: da denúncia da educação bancária ao anúncio de uma pedagogia libertadora. Pro-Posições, v. 27, n. 1 (79), p. 155-177, jan./abr. 2016. 
CAVALCANTE, S. M. S. O fenômeno da intertextualidade em uma perspectiva cognitiva. 2009. Tese (Doutorado em Estudos Linguísticos) - Faculdade de Letras, Universidade de Minas Gerais, Belo Horizonte, 2009.

CORTELLA, M. S. Paulo Freire: um pensamento clássico e atual. Revista e-Curriculum, São Paulo, v. 7, n. 3, 2011. Disponível em: <https://revistas.pucsp.br/index.php/curriculum/article/view/7590>. Acesso em: 09 mar. 2021. http://dx.doi.org/10.15603/1982-8993/ml.v1n2p23-35

COSSE, I. Mafalda: Middle Class, Everyday Life, and Politics in Argentina, 1964-1973. Hispanic American Historical Review, Durham, v. 94, n. 1, p. 35-75, 2014. https://doi.org/10.1215/00182168-2390604

DOURADO, L. F. Políticas e gestão da educação básica no Brasil: limites e perspectivas. Educação \& Sociedade, Campinas, v. 28, n. 100, 2007. Disponível em: <https://www.scielo.br/scielo.php?script=sci_arttext\&pid=S0101-73302007000300014>. Acesso em: 12 mar. 2021. https://doi.org/10.1590/S0101-73302007000300014

FONSECA, J. J. S. Metodologia da pesquisa científica. Fortaleza: UEC, 2002.

FRAZÃO, D. Biografia de Quino. ebiografia. Disponível em: <https://www.ebiografia.com/quino/>. Acesso em: 12 de mar. 2021.

FREIRE, P. A importância do ato de ler: em três artigos que se completam. São Paulo. Editora Cortez, 2019.

Carta de Paulo Freire aos professores. Estudos Avançados, [S. I.], v. 15, n. 42, p. 259-268, 2001. Disponível em: <https://www.revistas.usp.br/eav/article/view/9805>. Acesso em: 11 mar. 2021.

. Educação como prática da liberdade. São Paulo: Editora Paz \& Terra. 2020.

Pedagogia da autonomia. São Paulo: Editora Paz \& Terra. 2020a.

Pedagogia do oprimido. São Paulo: Editora Paz \& Terra. 2020b.

Política e educação. São Paulo: Cortez Editora, 1993.

IFTM. Ata da $1^{a}$ Reunião Extraordinária do Conselho Superior do IFTM, 2020. Disponível em: <https://iftm.edu.br/visao/loader.php?src=ae6e42d101eb94eff73a78473bf77c64>. Acesso em: 10 mar. 2021.

IFTM. Conhecendo o Instituto Federal de Educação, Ciência e Tecnologia do Triângulo Mineiro, 2016. Disponível em: <https://iftm.edu.br/acesso-a-informacao/institucional/documentos/Portfolio.pdf>. Acesso em: 10 mar. 2021.

PADILHA, P. R. Educação em direitos humanos sob a ótica dos ensinamentos de Paulo Freire. Revista Múltiplas Leituras, São Paulo, v. 1, n. 2, p. 23-35, 2008. Disponível em: <https://www.metodista.br/revistas/revistas-metodista/index.php/ML/article/view/1541>. Acesso em: 10 mar. 2021. https://doi.org/10.15603/1982-8993/ml.v1n2p23-35 


\section{Anexos}

Anexo A

2) A partir de la lectura del Texto 1, marca la opción correcta.

$31 / 32$ respostas corretas

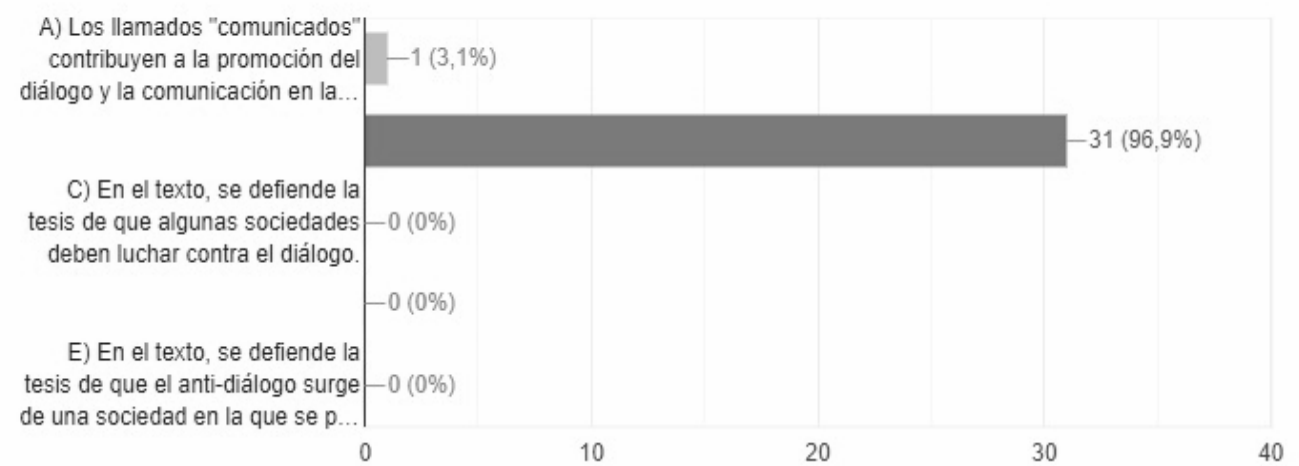

Figura 6. Resultados da prática educacional aplicada à turma de terceiro ano de Logística (questão 2).

Fonte: Material produzido pelos autores.

\section{Anexo B}

1) A partir de la lectura del Texto 1, marca la opción correcta.

$22 / 31$ respostas corretas

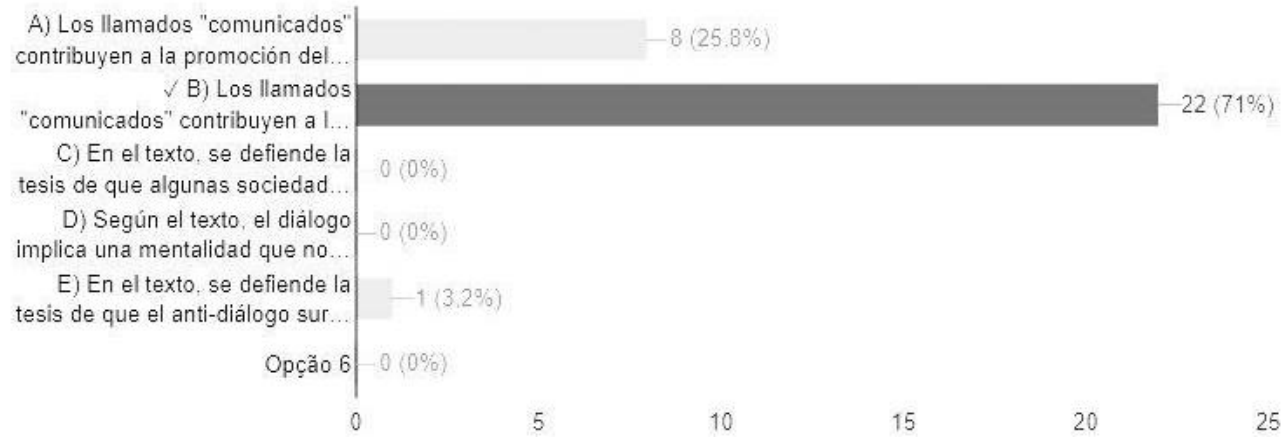

Figura 7. Resultados da prática educacional aplicada à turma de terceiro ano de Eletrotécnica (questão 2).

Fonte: Material produzido pelos autores.

\section{Anexo C}

\section{2) ¿El Texto 2 presenta una sociedad en que hay diálogo, según la concepción de diálogo del Texto 1? Justifique.}

0 Texto 2 não apresenta uma sociedade em que há diálogo, segundo a concepção de diálogo do Texto 1, uma vez que o povo não foi ouvido pelo orador; este, na verdade, foi o único a que foi permitido falar, propagando, assim, sua visão, e desconsiderando as opiniões da população.

Figura 8. Resposta de um estudante da turma de terceiro ano de Eletrotécnica (questão 3).

Fonte: Material produzido pelos autores.

LínguaTec, Instituto Federal de Educação, Ciência e Tecnologia do Rio Grande do Sul, Bento Gonçalves v. 6, n. 1 , p. 34-52, jun. 2021. 


\begin{abstract}
Anexo D
4) ¿Cómo las dos escenas del medio del cartoon se relacionan con el concepto freireano de mutismo, presente en el Texto 1? Explique.

Elas se relacionam com este conceito pois fica evidente que houve apenas um monólogo, um discurso de apenas uma pessoa para uma multidão que nem mesmo questionou ou formou críticas àquilo que foi dito, sendo considerado, portanto, mutismo.
\end{abstract}

Figura 9. Resposta de um estudante da turma de terceiro ano de Logística (questão 4).

Fonte: Material produzido pelos autores.

\begin{abstract}
Anexo $\mathrm{E}$
5) ¿Qué significa la representación de pensamiento en la última escena del cartoon, en que la personaje está en su cama? ¿Por que es distinta de la representación del discurso en la tercera escena?
\end{abstract}

Eu penso que nessa cena, o político está com seus reais pensamentos que diferem do que ele disse, provavelmente seu discurso foi sobre algo que a população gostaria de ouvir, mas ele, na verdade, possui uma maneira diferente e distorcida de pensar.

Figura 10. Resposta de um estudante da turma de terceiro ano de Logística (questão 5).

Fonte: Material produzido pelos autores.

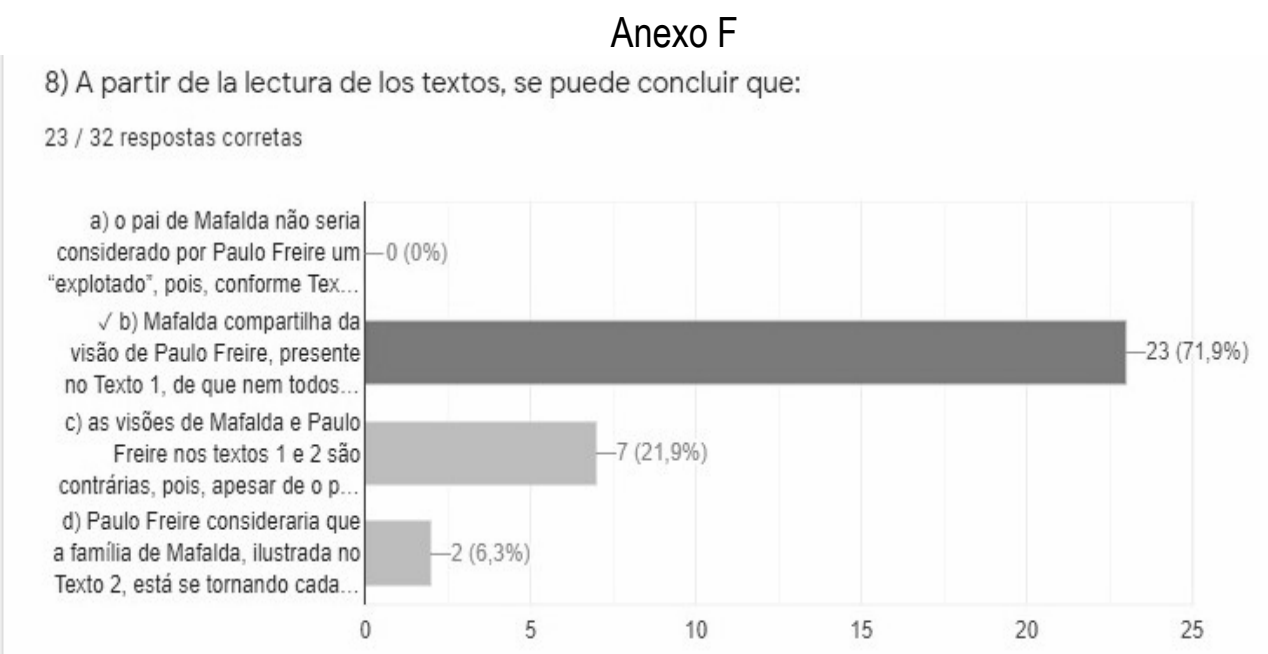

Figura 11. Resultados da prática educacional aplicada à turma de segundo ano de Eletrotécnica.

Fonte: Material produzido pelos autores.

LínguaTec, Instituto Federal de Educação, Ciência e Tecnologia do Rio Grande do Sul, Bento Gonçalves 


\section{Anexo G}

8) A partir de la lectura de los textos, se puede concluir que:

$23 / 25$ respostas corretas

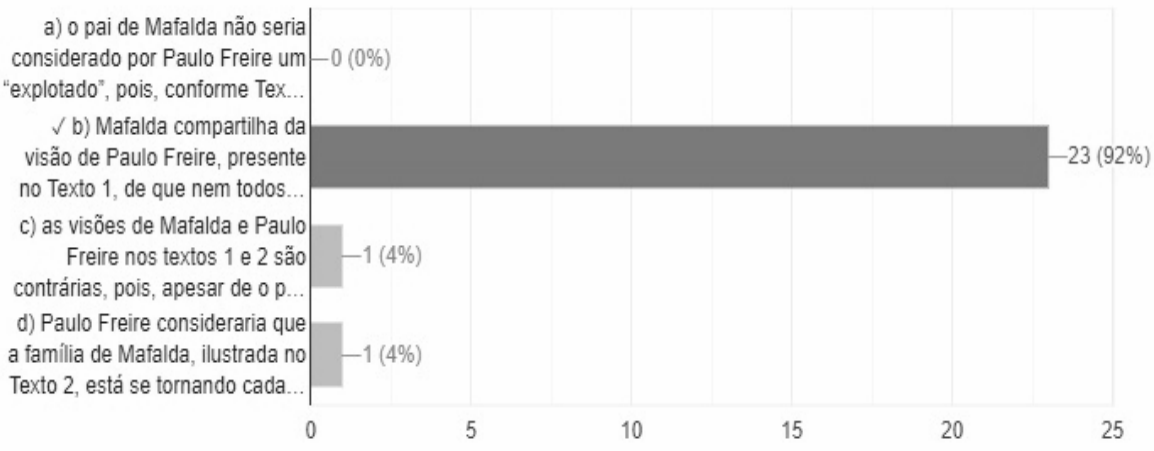

Figura 12. Resultados da prática educacional aplicada à turma de segundo ano de Logística.

Fonte: Material produzido pelos autores.

\section{Anexo $\mathrm{H}$}

8) A partir de la lectura de los textos, se puede concluir que:

$15 / 24$ respostas corretas

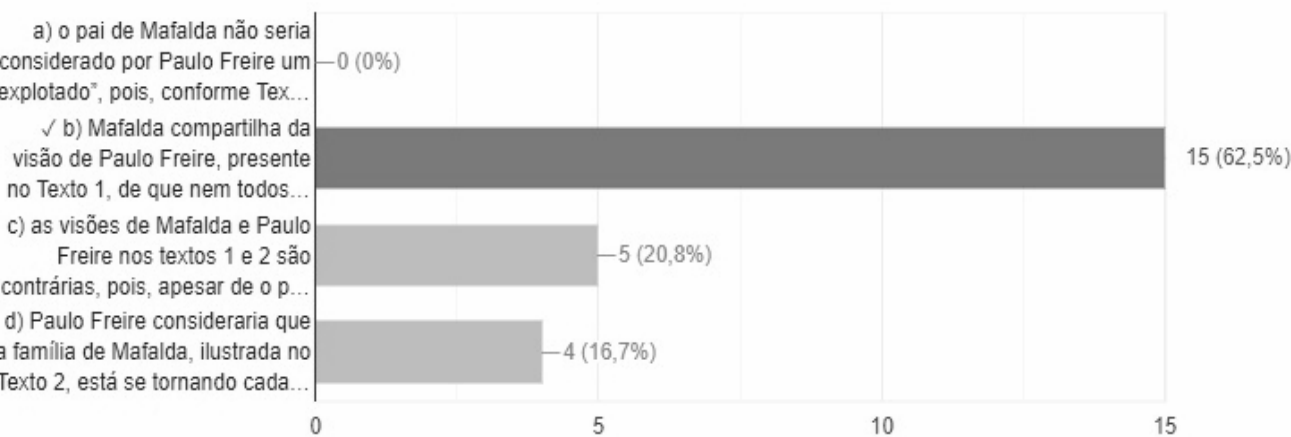

Figura 13. Resultados da prática educacional aplicada à turma de segundo ano de Mineração.

Fonte: Material produzido pelos autores.

Data de submissão: 14/03/2021. Data de aprovação: 15/04/2021.

LínguaTec, Instituto Federal de Educação, Ciência e Tecnologia do Rio Grande do Sul, Bento Gonçalves 